\title{
Metabolism of praziquantel in kingfish Seriola lalandi
}

\author{
L. Tubbs ${ }^{1, *}$, T. Mathieson ${ }^{1}$, M. Tingle ${ }^{2}$ \\ ${ }^{1}$ National Institute of Water and Atmospheric Research (NIWA), PO Box 109 695, Auckland, New Zealand \\ ${ }^{2}$ Department of Pharmacology and Clinical Pharmacology, University of Auckland, Private Bag 92019, Auckland, New Zealand
}

\begin{abstract}
Investigations into the metabolism of drugs used in aquatic animal therapy are useful for understanding the mechanisms of xenobiotic transformation systems and can aid the development of dosing regimens. This study investigated the metabolism of the synthetic anthelmintic praziquantel, which has application in helminthiasis treatment for several fish species including kingfish Seriola lalandi, a commercial aquaculture finfish species. At least 7 mono- or dihydroxylated derivatives of the parent compound were identified in kingfish after administration of a $150 \mathrm{mg} \mathrm{kg}^{-1}$ oral praziquantel dose, paralleling findings in mammals. The structure of one representative mono-hydroxylated species that was prominent in the skin, muscle, liver, kidney and plasma of kingfish was investigated using fragmentation experiments; this revealed that hydroxylation of the parent molecule occurred in the tetrahydroisoquinoline region of praziquantel, analogous with mammalian metabolites, but different to that of the active mammalian metabolite (trans-4-OH-praziquantel). The implications of these findings with regard to biotransformation systems for this drug in mammals and fish are discussed.
\end{abstract}

KEY WORDS: Praziquantel $\cdot$ Anthelmintic $\cdot$ Xenobiotic $\cdot$ Metabolism $\cdot$ Kingfish $\cdot$ Seriola lalandi Resale or republication not permitted without written consent of the publisher

\section{INTRODUCTION}

Praziquantel (PZQ; Fig. 1) is a broad-spectrum anthelmintic widely used in veterinary and human helminthiasis (Schepmann \& Blaschke 2001, Chen 2005). In captive fish, the drug has proven effective against monogeneans infecting the gills, skin or branchial cavities (Schmahl \& Mehlhorn 1985, Schmahl \& Taraschewski 1987, Thoney 1990, Kim et al. 1998, Hirazawa et al. 2000, Chisholm \& Whittington 2002, Janse \& Borgsteede 2003, Stephens et al. 2003, Hirazawa et al. 2004, Sharp et al. 2004), larval and encysted digeneans infecting the eyes (Bylund \& Sumari 1981) and skin (Mitchell 1995), plus intestinal cestodes (Sanmartin Duran et al. 1989) of teleosts and elasmobranchs. In many cases the drug has been administered as a bath treatment, but oral preparations have also been investigated for aquaria or aquaculture use.
The drug is usually administered in racemic form, although its efficacy is attributed to the R-(-)-enantiomer while the $\mathrm{S}-(+)$-enantiomer is considered ineffective (Andrews et al. 1983, Xiao \& Catto 1989, Staudt et al. 1992). In mammals, enteral absorption of orally administered PZQ is rapid and virtually complete with the drug, which undergoes extensive first pass metabolism in the liver, being excreted in urine along with metabolites (Buehring et al. 1978, Diekmann 1979, Andrews et al. 1983, Dayan 2003).

Several mammalian studies on the metabolism of PZQ have been reported in the open literature to aid the optimisation of dosing regimens in clinical practice. These studies have identified mono- and dihydroxy derivatives as the principal mammalian metabolites of PZQ, where hydroxylation occurs in both the tetrahydroisoquinoline and cyclohexyl regions of the parent compound (Andrews et al. 1983, Lerch \& Blaschke 1998, Meier \& Blaschke 2000, 2001, Schepmann \& 


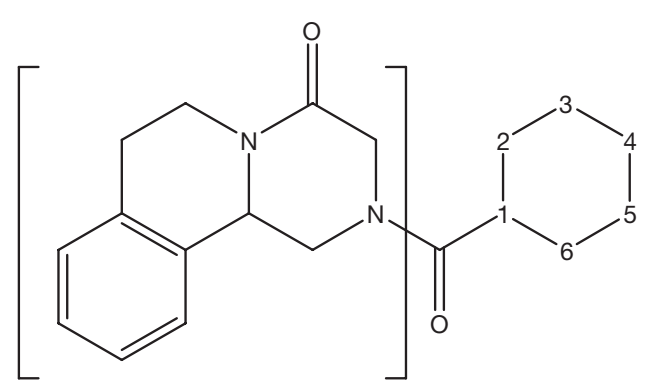

Fig. 1. Chemical structure of praziquantel. Cyclohexyl carbons are numbered from 1 to 6 ; tetrahydroisoquinoline region of the molecule in brackets

Blaschke 2001). The major product of oxidative PZQ metabolism has been identified as the 4-hydroxycyclohexyl analogue (4-OH-PZQ), which may exist in cis or trans configuration (Kiec-Kononowicz et al. 1991); interestingly, the trans- variant of this metabolite, trans-4-OH-PZQ, has shown a degree of anthelmintic activity against the helminth Schistosoma mansoni, both in vitro and in vivo (Andrews et al. 1983, Xiao et al. 1991, Staudt et al. 1992).

Several enzymes responsible for the hepatic metabolism of PZQ to hydroxylated species have recently been identified in mammals; these include several phenobarbitone-inducible members of the cytochrome 450 (CYP) family, namely CYP1A2, CYP2C19 and CYP3A4 (Giorgi et al. 2001, 2003, Li et al. 2003). Interestingly, a number of mammalian CYP homologues have also been identified in fish. A 400 bp cDNA fragment from mummichog Fundulus heteroclitus liver RNA was 57 to $70 \%$ identical to the corresponding region of mammalian CYP3A genes (Celander \& Stegeman 1997). Furthermore, appreciable amounts of CYP3A-like proteins have been found in several teleostean species (Stegeman et al. 1997). These findings raise the possibility that hydroxylated PZQ metabolites, similar to those produced by mammals and with potential anthelmintic activity, may be produced by fish dosed with this drug.

The metabolism of xenobiotics such as PZQ are of interest in fish, particularly if biotransformation products contribute to the efficacy of a drug. During the development of an assay to describe the pharmacokinetics of orally administered PZQ in kingfish Seriola lalandi (Tubbs \& Tingle 2006a,b), several metabolites were isolated using HPLC. One metabolite in particular was prominent in all kingfish tissues examined, with the largest concentration occurring in kingfish liver. The present study aimed to investigate the structure of this representative metabolite and compare it with the active mammalian excretion metabolite trans-
4-OH-PZQ; this was done as a first step in understanding the metabolism of PZQ in kingfish and to determine whether metabolites might contribute toward the efficacy of an orally administered PZQ dose in kingfish.

\section{MATERIALS AND METHODS}

Fish. All fish used in these experiments were 2 yr old (3.0 kg average weight) hatchery-reared juvenile kingfish supplied by the National Institute of Water and Atmospheric Research (NIWA). Fish were maintained at NIWA's Bream Bay aquaculture facility $\left(35^{\circ} 49^{\prime} \mathrm{S}, 174^{\circ} 30^{\prime} \mathrm{E}\right)$ in a standard $10000 \mathrm{l}$ flowthrough filtered seawater holding tank at ambient temperature $\left(18\right.$ to $\left.19^{\circ} \mathrm{C}\right)$ with an exchange rate of approximately $10 \% \mathrm{~h}^{-1}$. Prior to conducting experiments the fish were starved for $3 \mathrm{~d}$.

To obtain PZQ metabolites, 3 anaesthetised kingfish (3.0 kg average weight) were orally dosed with $150 \mathrm{mg}$ $\mathrm{kg}^{-1} \mathrm{PZQ}$ dissolved in DMSO (0.5 ml kg-1 BW) administered directly to the stomach by intubation. Anaesthesia was achieved by bathing fish in 300 ppm 2-phenoxyethanol for 4 to $5 \mathrm{~min}$ to induce Stage V anaesthesia (total loss of reactivity, Cho \& Heath 2000). Afterward, fish were transferred to fresh seawater to recover. Ninety minutes later each fish was killed by spinal severance; skin, liver, kidney, muscle and plasma (following separation of blood at $3000 \times g$ for $5 \mathrm{~min}$ ) were then collected, placed on dry ice and transferred to $-80^{\circ} \mathrm{C}$ until analysed.

Sample preparation. Tissue samples from the 3 fish were pooled prior to extraction and analysis. Internal standard diazepam (800 ng 7-chloro-1-methyl5-phenyl-3H-1,4-benzo-diazepin-2[1H]-one; Sigma Chemical) was added to samples to compare recovery against a previous study (Tubbs \& Tingle 2006a). The method of Rogstad et al. (1987) was then modified to isolate metabolites. Pieces of skin, liver, kidney and muscle $(0.5 \mathrm{~g})$ or plasma $(200 \mu \mathrm{l})$ were placed in $10 \mathrm{ml}$ glass tubes and homogenised (IKA T25, Wolf Laboratories) with ethyl acetate $(2 \times 1 \mathrm{ml})$ except plasma, which was mixed with a vortex mixer. The displaced supernatants $(3000 \times g$ for $5 \mathrm{~min})$ were dried in a rotary evaporator under vacuum at $20^{\circ} \mathrm{C}$ (SC 110A SpeedVac, Thermo Savant). Dried residues were resuspended in $2.5 \mathrm{ml}$ hexane, vortex mixed and loaded onto activated silica columns (Isolute $500 \mathrm{mg}$ SI, International Sorbent Technology) under vacuum. The columns were then rinsed with $2.5 \mathrm{ml} 15 \%$ diethyl ether:hexane v/v). Praziquantel and metabolites were then eluted using 2 successive rinses of $2.5 \mathrm{ml} 70 \% \mathrm{v} / \mathrm{v}$ acetone:hexane; this was evaporated as described. The dried residue was resuspended in $200 \mu \mathrm{l}$ ethanol and a $50 \mu \mathrm{l}$ aliquot 
was injected into the HPLC. Previous validation compared with recovery of the internal standard in the present study indicated that this method provides over $85 \%$ recovery for PZQ from kingfish skin and plasma (Tubbs \& Tingle 2006a).

Analytical conditions (HPLC/UV). Samples were analysed using a Thermo-Finnigan Surveyor HPLC/ UV. The analytical separation of PZQ and potential metabolites was performed on a Phenomenex Luna C18(2) column $(150 \times 3.0 \mathrm{~mm}$ i.d., $5 \mu \mathrm{m}$ particle size $)$. A previous study revealed that a gradient method could be used to separate PZQ metabolites from rat liver microsomes with HPLC (Lerch \& Blaschke 1998). Aliquots from kingfish dosed with $\mathrm{PZQ}$ were run on a gradient consisting of acetonitrile:water, starting at 16:84 v/v and increasing up to $38 \%$ acetonitrile over $40 \mathrm{~min}$. Several possible metabolites were separated in this manner, with the highest diversity detected in the liver. One potential metabolite with a retention time of 26.3 min was present in all of the tissues examined (see Fig. 2).

In an effort to reduce the sample run time used with the gradient method previously described, but to maintain the resolution of metabolites, an isocratic mobile phase was used with a higher aqueous content than that used previously by Kim et al. (2001) for PZQ resolution from fish tissue. As recovery had been established, no internal standard (diazepam) was added to these samples. An isocratic mixture of 35:65 v/v acetonitrile:water with a constant flow rate of $1 \mathrm{ml} \mathrm{min}^{-1}$ was able to separate several PZQ metabolites and parent PZQ with a run time of 30 min (see Fig. 3).

Analytical conditions (liquid chromatography/mass spectrometry, LC/MS). Samples were analysed using a Thermo-Finnigan LCQ Ion Trap. The mass spectrometer was operated with the following parameters: scan mode, positive ion from 200 to 1000 atomic mass units (amu); sheath gas flow, 80 arbitary units of $\mathrm{N}_{2}$; auxiliary gas flow, 10 arbitary units of $\mathrm{N}_{2}$ i spray voltage, $4 \mathrm{kV}$; capillary temperature, $240^{\circ} \mathrm{C}$.

Preparative conditions (HPLC/UV). The PZQ metabolite (later identified as M7; see 'Results') that was prominent in kingfish liver, kidney, skin, muscle and plasma (retention time $=26.3 \mathrm{~min}$; Fig. 2) was purified with a Waters preparative HPLC/UV Auto-Purification system using extracts of kingfish liver only. The preparative separation of this metabolite was carried in a Waters Xterra $150 \mathrm{~mm} \times 19.0 \mathrm{~mm}$ column with a particle size of $5 \mu \mathrm{m}$. Extract samples $(150 \mu \mathrm{l})$ were injected repetitively into an isocratic solution of 35:65 v/v acetonitrile:water $\left(14 \mathrm{ml} \mathrm{min}^{-1}\right)$.

MS fragmentation. Additional MS fragmentation studies were performed on 3 ions to gain information on the specific kingfish metabolite M7. Either $\mathrm{H}^{+}$or $\mathrm{Na}^{+}$adducts were fragmented in $\mathrm{MS}^{2}$ experiments from pure solutions of parent $P Z Q$, the mammalian metabolite trans-4-OH-PZQ and M7. Methanol solutions were analysed by direct infusion into an LCQ Ion Trap Mass Spectrometer using a syringe pump at a

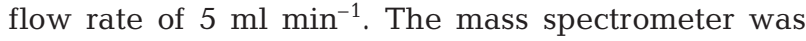
operated with the following LCQ parameters: scan mode, positive ion from 200 to $1000 \mathrm{amu}_{\text {; sheath gas }}$ flow, 20 arbitary units of $\mathrm{N}_{2}$; auxiliary gas flow, 0 arbitary units of $\mathrm{N}_{2}$; spray voltage $4 \mathrm{kV}$; capillary temperature, $200^{\circ} \mathrm{C}$. Controlled $\mathrm{MS}^{\mathrm{n}}$ fragmentation was performed on the most abundant ion for each solution, 313.13 mass-to-charge ratio $(\mathrm{m} / \mathrm{z})[\mathrm{PZQ}+\mathrm{H}]^{+}$, $329.2 \mathrm{~m} / \mathrm{z}$ [trans-4-OH-PZQ+H$]^{+}$and $351.13 \mathrm{~m} / \mathrm{z}$ $[\mathrm{M} 7+\mathrm{Na}]^{+}$, with relative collision energies ranging from 25 to $30 \%$.

\section{RESULTS}

Separation of several compounds extracted from PZQ-dosed kingfish liver was adequately achieved using Reverse Phase HPLC (Fig. 3). Using LC/MS analysis, the compound forming the base peak was identified as the $\mathrm{H}^{+}$adduct of the parent compound $(\mathrm{PZQ}+\mathrm{H})^{+}=313.13 \mathrm{~m} / \mathrm{z}[\mathrm{x}]$. A further 7 compounds were identified as $\mathrm{H}^{+}$or $\mathrm{Na}^{+}$adducts of hydroxylated PZQ metabolites. The most abundant ion of the metabolite peaks (M1, M3, M5 and M6) was $329.2 \mathrm{~m} / \mathrm{z}$ [ $x+16]$ (Fig. 4), indicating hydroxylation of the PZQ molecule (Fig. 4A). For M2 and M7 $329.2 \mathrm{~m} / \mathrm{z}$ was detected (Fig. 4B), but a prominent ion at $311.2 \mathrm{~m} / \mathrm{z}$ was also observed, indicating loss of water from the mono-hydroxylated PZQ species $[x+16-18 ; x+\mathrm{OH}-$ $\mathrm{H}_{2} \mathrm{O}$ ]. Water loss is a common phenomenon in the MS of hydroxylated organic compounds (R-OH) and occurs through the formation of a $-\mathrm{C}=\mathrm{C}$ - double bond by eliminating an $\mathrm{H}_{2} \mathrm{O}$ molecule from the - $\mathrm{C}(\mathrm{H})-\mathrm{C}(\mathrm{OH})$ - structural moiety. An ion of $327.07 \mathrm{~m} / \mathrm{z}$ was observed for the separated M4 metabolite. This corresponds to water loss from a dihydroxylated PZQ species $\left[x+32-18 ; x+2 \mathrm{OH}-\mathrm{H}_{2} \mathrm{O}\right]$ (Fig. $4 \mathrm{C}$ ).

Further fragmentation of PZQ in the ion trap $\left(\mathrm{MS}^{2}\right)$ showed a peak at $203.13 \mathrm{~m} / \mathrm{z}$ (Fig. 5), which corresponded to the $\mathrm{H}^{+}$adduct of the tetrahydroisoquinoline group after loss of the cyclohexyl moiety. $\mathrm{MS}^{2}$ analysis of trans-4-OH-PZQ yielded the dehydro ion $(311.14 \mathrm{~m} / \mathrm{z}$ ) and the $203.1 \mathrm{~m} / \mathrm{z}$ ion (Fig. 6), which is consistent with the fragmentation pattern of PZQ since the OH group in trans-4-OH-PZQ is known to occur on the cyclohexyl ring (Andrews et al. 1983).

In contrast, $\mathrm{MS}^{2}$ fragmentation of the $\mathrm{Na}^{+}$adduct of M7 (351.1 m/z) yielded an ion of $201.07 \mathrm{~m} / \mathrm{z}$ (Fig. 7), not $203.1 \mathrm{~m} / \mathrm{z}$ as for PZQ and trans-4-OH-PZQ. This is consistent with the formation of a double bond in the tetrahydroisoquinoline moiety (after hydroxylation and 
water loss), indicating that hydroxyl addition had not occurred on the cyclohexyl moiety of M7. Two additional dehydro fragments, both assigned as $\mathrm{Na}^{+}$ adducts, were observed at 333.13 and $223 \mathrm{~m} / \mathrm{z}$ during $\mathrm{MS}^{2}$ of M7. Their proposed structures (Fig. 7) are also consistent with hydroxylation and subsequent water loss from the tetrahydroisoquinoline group.

Although it was determined that M7 hydroxylation occurred in a different region of the molecule than trans-4-OH-PZQ, the exact position of hydroxylation in the M7 tetrahydroisoquinoline moiety was not known. However, the complete process of hydroxylation, water loss and $\mathrm{C}=\mathrm{C}$ bond formation is possible only in specific regions of the tetrahydroisoquinoline moiety. Our proposed alternative structures for the dehydro $201.07 \mathrm{~m} / \mathrm{z}$ ion are depicted in Fig. 7, each with a unique $\mathrm{C}=\mathrm{C}$ bond position.
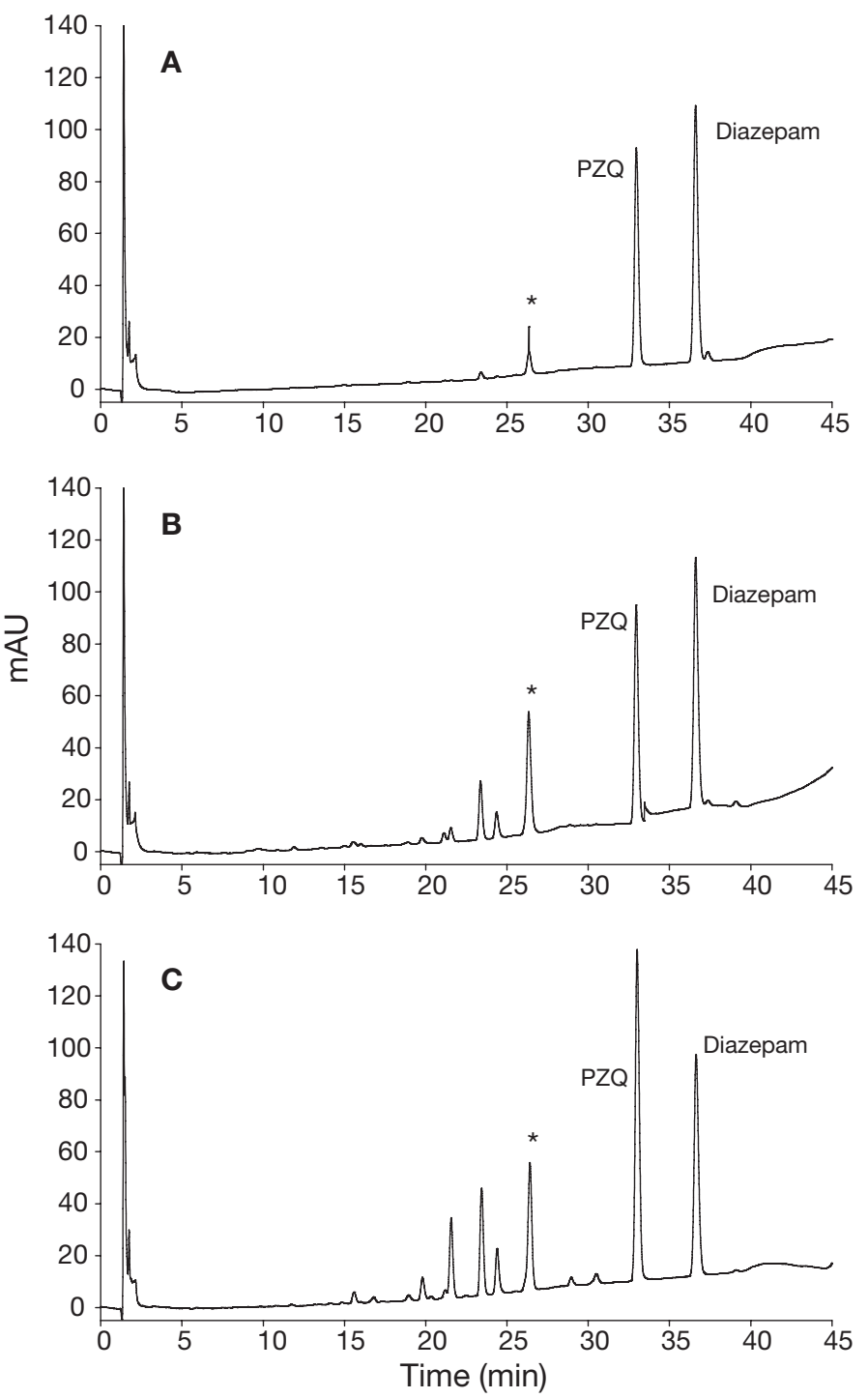

\section{DISCUSSION}

The hydroxylation of PZQ by kingfish reported in the present study demonstrates a similarity between different types of vertebrates and their xenobiotic biotransformation systems. A number of studies have demonstrated that hydroxylation predominantly occurs in the cyclohexyl ring of mammals dosed with PZQ (Lerch \& Blaschke 1998, Meier \& Blaschke 2001, Schepmann \& Blaschke 2001). However, the fragmentation pattern of the kingfish metabolite is consistent with the proposed structure of the only PZQ metabolite recovered from lambs reported by Giorgi et al. (2001); this study postulated that infection with Fasciola hepatica influences the metabolic profile of $\mathrm{PZQ}$ through modification of mixed-function oxidase (CYP) activity.
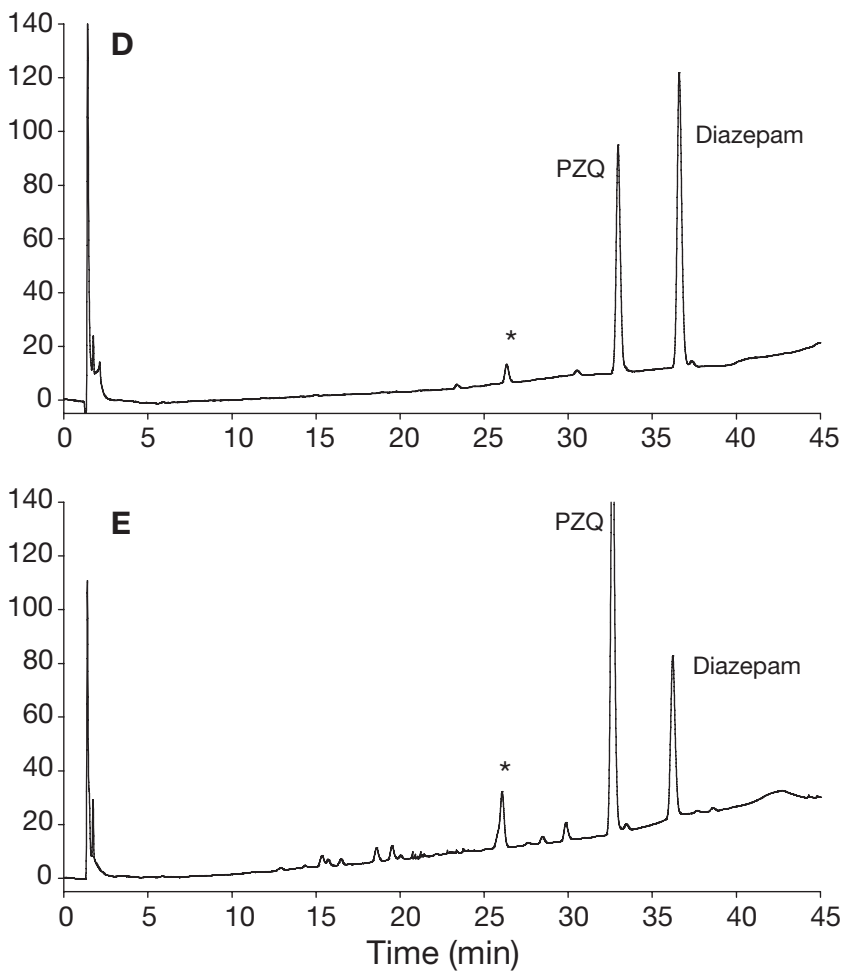

Fig. 2. Seriola lalandi. UV chromatograms of kingfish orally dosed with $150 \mathrm{mg} \mathrm{kg}^{-1}$ praziquantel (PZQ), resolved using acetonitrile:water gradient (after Lerch \& Blaschke 1998). (A) Muscle, (B) kidney, (C) liver, (D) skin, (E) plasma. Note the PZQ metabolite $\left({ }^{*}\right.$, retention time $\left.=26.3 \mathrm{~min}\right)$ present in all tissues examined 
Several factors implicate the importance of microsomal mixed-function oxidase (MFO) activity in the metabolism of lipid-soluble compounds such as PZQ in kingfish. These include the known role of CYP enzymes in mammalian PZQ metabolism, the homology between these enzymes in fish and mammals, and the presence of appreciable levels of CYP-related pro- teins in fish. If the MFO enzyme system was responsible for the formation of metabolites observed in the present study, the presence of 7 mono-hydroxylated variants in kingfish liver may also be a reflection of the low specificity of mixed-function oxidase systems in fish, which is a well-known characteristic of these enzymes in vertebrates (Chambers \& Yarbrough 1976).

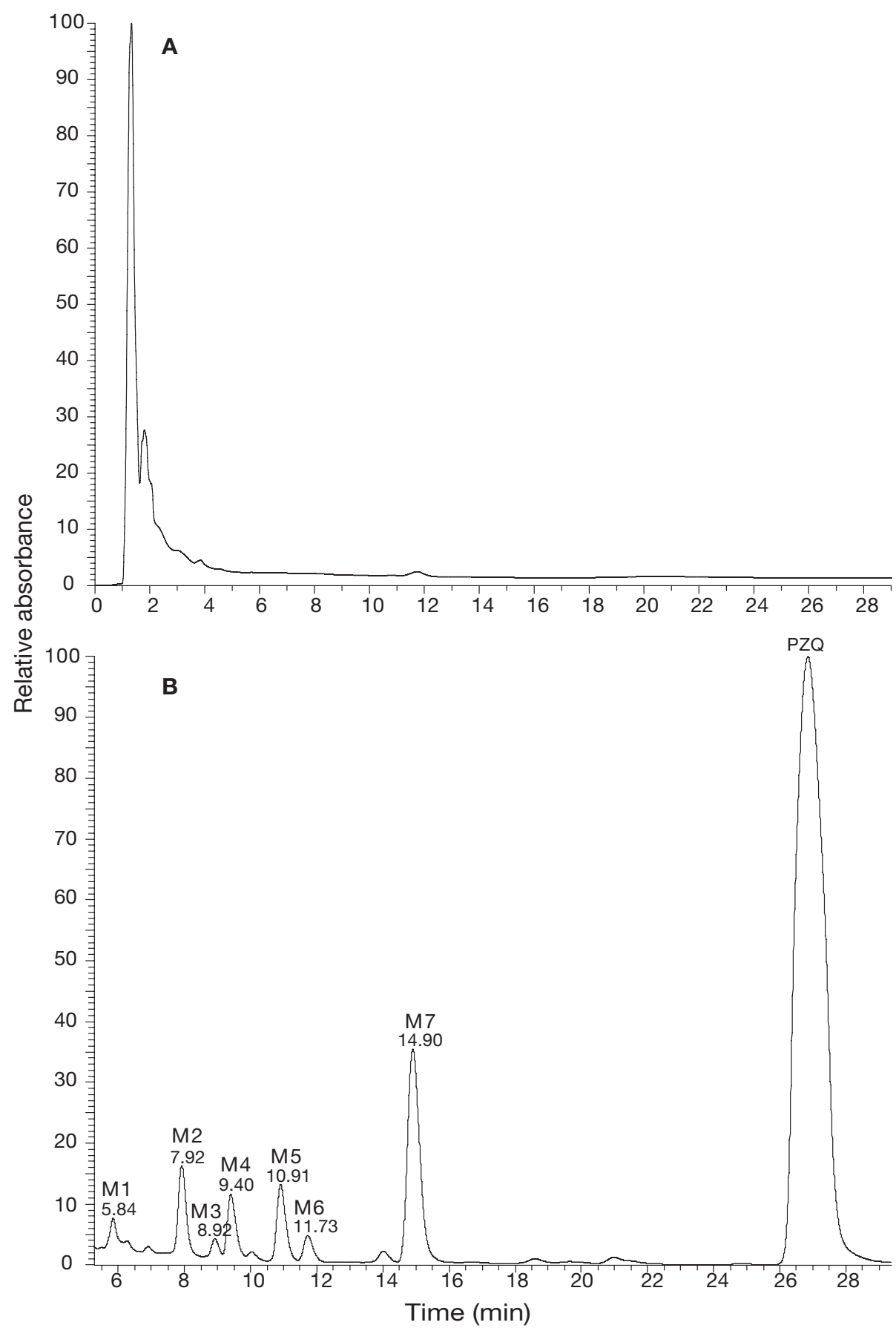

Fig. 3. UV Seriola lalandi. Chromatograms of kingfish liver extract resolved using an isocratic mobile phase of 35:65 v/v acetonitrile:water. (A) Untreated, (B) post-administration of $150 \mathrm{mg} \mathrm{kg}^{-1}$ oral praziquantel (PZQ). Metabolites M1 to M7 correspond to mono- and dihydroxylated PZQ 
The location of the hydroxyl group on parent PZQ with respect to the anthelmintic potential of monohydroxylated metabolites remains uncertain. At least 3 studies have reported the in vitro anthelmintic activity of a mono-hydroxylated PZQ metabolite (trans-4-OH$P Z Q)$, but in all these studies the hydroxylation occurred in the cyclohexyl rather than tetrahydroisoquinoline region of the parent compound (Andrews et al. 1983, Xiao et al. 1991, Staudt et al. 1992). Interestingly, the first two of these studies indicated that a racemic mixture of this mono-hydroxylated metabolite had between 400-fold (Andrews et al. 1983) and 30fold lower (Xiao et al. 1991) anthelmintic potential than the parent compound. The third study, which separated enantiomers of the metabolite, found no apparent difference in efficacy between $\mathrm{R}-(-)-\operatorname{trans}-4-\mathrm{OH}-$

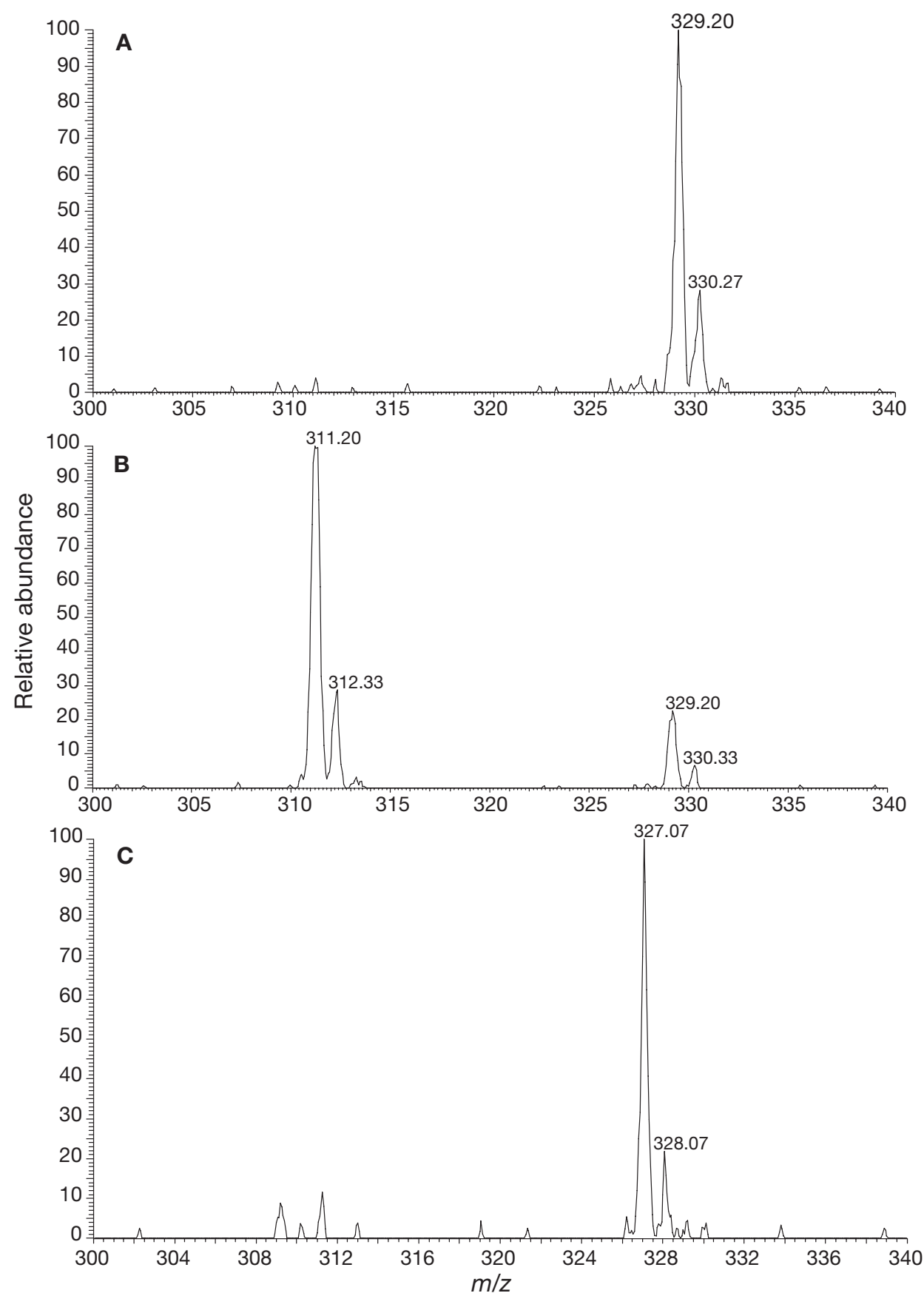

Fig. 4. Representative mass spectra of hydroxylated praziquantel (PZQ) metabolites (M). (A) M5, (B) M7, (C) M4. m/z: mass-tocharge ratio 


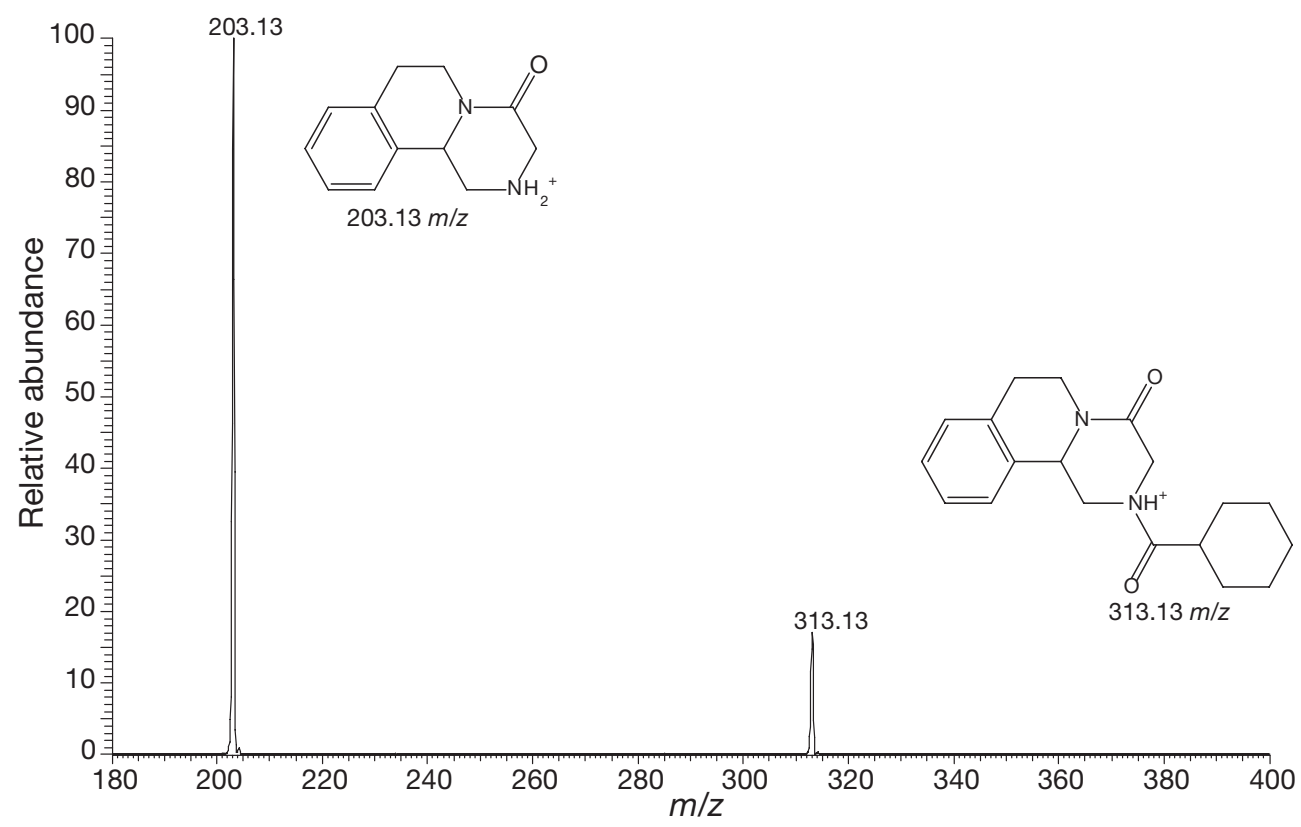

Fig. 5. $\mathrm{MS}^{2}$ of a praziquantel (PZQ) ion (313 mass-to-charge ratio, $\mathrm{m} / \mathrm{z}$ ) showing the $203 \mathrm{~m} / \mathrm{z}$ fragment

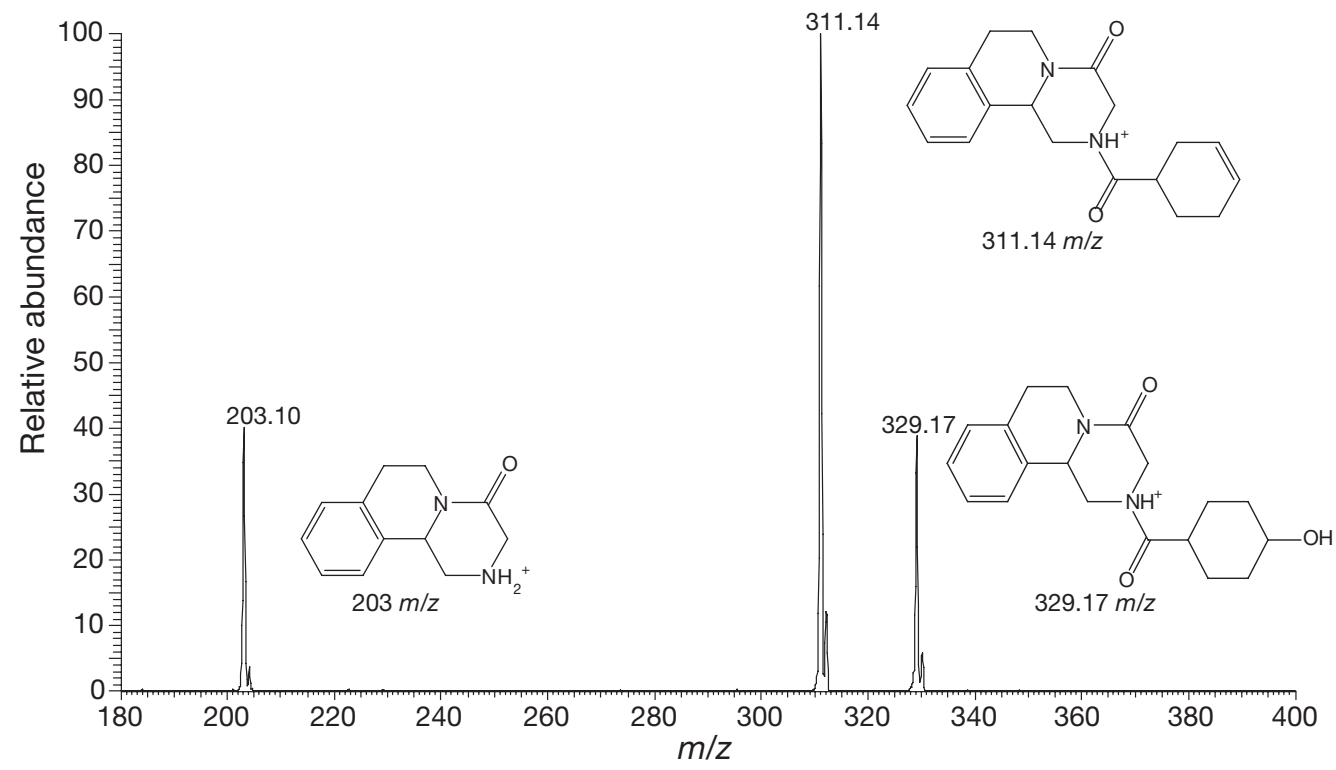

Fig. 6. $\mathrm{MS}^{2}$ of the trans-4-hydroxy-praziquantel (trans-4-OH-PZQ). m/z: mass-to-charge ratio

PZQ and the same enantiomer of PZQ (Staudt et al. 1992). It is plausible that some of the remaining monohydroxylated metabolites in the present study may have been formed through the location of the hydroxyl group on the cyclohexyl ring, as with trans-4-OH-PZQ. However, the fact that anthelmintic potential of racemic trans-4-OH-PZQ is low and that there appeared to be relatively small amounts of the other metabolites in kingfish tissue (at least, due to their rel- ative UV absorption; see below) suggests that the contribution to overall therapeutic efficacy of these metabolites may be minor.

Differences in both UV molar absorption coefficients $(\varepsilon)$ and ionisation potentials between PZQ and each metabolite preclude quantitative analysis of the observed UV and MS peaks. Furthermore, M7 exhibited the longest retention time in reverse-phase HPLC, indicating it was the least water soluble of the ob- 


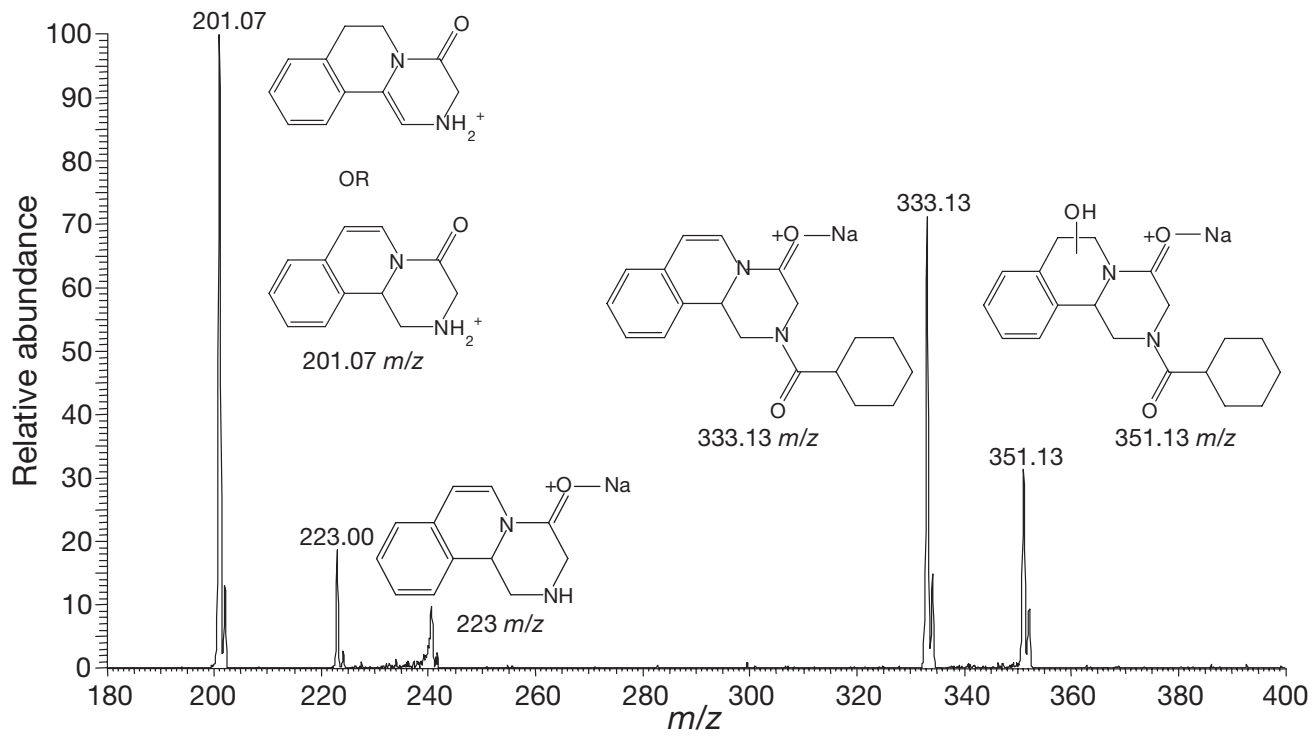

Fig. 7. $\mathrm{MS}^{2}$ of the kingfish praziquantel (PZQ) metabolite M7. Note that the positioning of the OH group on the $351 \mathrm{~m} / \mathrm{z}$ (massto-charge ratio) ion is indicative only and 2 alternative structures are depicted for the $201.07 \mathrm{~m} / \mathrm{z}$ fragment

served mono-hydroxylated metabolites. Therefore, M7 could be expected to have a relatively low excretion rate from kingfish.

In future, it may be useful to perform classical in vitro investigations on isolated kingfish microsomes or hepatocytes to investigate further the biotransformation pathways of drugs such as PZQ in this species This information may be useful to select potential enzyme inhibitors to influence the biotransformation of PZQ and, hence, modify drug clearance, thereby modifying the residence time of the active compound in treated fish. In addition, it would be interesting to determine whether the hydroxylation of PZQ creates a compound with anthelmintic activity against helminth parasites of kingfish.

Acknowledgements. The authors thank Profs. D. Schepmann and G. Blaschke, University of Münster, for the generous donation of trans-4-OH-PZQ. This work was part of the PhD project of L.T., which was supported by the New Zealand Foundation for Research, Science and Technology.

\section{LITERATURE CITED}

Andrews P, Thomas H, Pohlke R, Seubert J (1983) Praziquantel. Med Res Rev 3:147-200

Buehring KU, Diekmann HW, Mueller H, Garbe A, Nowak H (1978) Metabolism of praziquantel in man. Eur J Drug Metabol Pharm 3:179-190

Bylund G, Sumari O (1981) Laboratory tests with Droncit against diplostomiasis in rainbow trout, Salmo gairdneri Richardson. J Fish Dis 4:259-264

Celander M, Stegeman JJ (1997) Isolation of a cytochrome P450 3A cDNA sequence (CYP3A30) from the marine teleost Fundulus heteroclitus and phylogenetic analyses of CYP3A genes. Biochem Biophys Res Commun 236: 306-312

Chambers JE, Yarbrough JD (1976) Xenobiotic bio-transformation systems in fishes. Comp Biochem Physiol C Comp Pharmacol 55:77-84

Chen MG (2005) Use of praziquantel for clinical treatment and morbidity control of schistosomiasis japonica in China: a review of 30 years' experience. Acta Trop 96: 168-176

Chisholm LA, Whittington ID (2002) Efficacy of praziquantel bath treatments for monogenenean infections of the Rhinobatos typus. J Aquat Anim Health 14:230-234

Cho GK, Heath DD (2000) Comparison of tricaine methanesulphonate (MS222) and clove oil anaesthesia effects on the physiology of juvenile chinook salmon Oncorhynchus tshawytscha (Walbaum). Aquacult Res 31:537-546

Dayan AD (2003) Albendazole, mebendazole and praziquantel. Review of non-clinical toxicity and pharmacokinetics. Acta Trop 86:141-159

Diekmann HW (1979) Quantitative determination of praziquantel in body fluids by gas liquid chromatography. Eur J Drug Metabol Pharm 4:139-142

Giorgi M, Salvatori AP, Soldani G, Giusiani M, Longo V, Gervasi PG, Mengozzi G (2001) Pharmacokinetics and microsomal oxidation of praziquantel and its effects on the P450 system in three-month-old lambs infested by Fasciola hepatica. J Vet Pharmacol Ther 24:251-259

> Giorgi M, Meucci V, Vaccaro E, Mengozzi G, Giusiani M, Soldani G (2003) Effects of liquid and freeze-dried grapefruit juice on the pharmacokinetics of praziquantel and its metabolite 4 '-hydroxy praziquantel in beagle dogs. Pharm Res 47:87-92

Hirazawa N, Ohtaka T, Hata K (2000) Challenge trials on the anthelmintic effect of drugs and natural agents against the monogenean Heterobothrium okamotoi in the tiger puffer Takifugu rubripes. Aquaculture 188:1-13

Hirazawa N, Mitsuboshi T, Hirata T, Shirasu K (2004) Susceptibility of spotted halibut Verasper variegatus (Pleuronec- 
tidae) to infection by the monogenean Neobenedenia girellae (Capsalidae) and oral therapy trials using praziquantel. Aquaculture 238:83-95

Janse M, Borgsteede FHM (2003) Praziquantel treatment of captive white-spotted eagle rays (Aetobatus narinari) infested with monogenean trematodes. Bull Eur Assoc Fish Pathol 23:152-156

Kiec-Kononowicz K, Farghaly ZS, Blaschke G (1991) Synthesis and properties of cis-4 hydroxypraziquantel and trans-4 hydroxypraziquantel. Arch Pharm (Weinheim) 324:235-238

Kim KH, Park SI, Jee BY (1998) Efficacy of oral administration of praziquantel and mebendazole against Microcotyle sebastis (Monogenea) infestations of cultured rockfish (Sebastes schlegeli). Fish Pathol 33:467-471

Kim KH, Kim CS, Kim JW (2001) Depletion of praziquantel in plasma and muscle tissue of cultured rockfish Sebastes schlegeli after oral and bath treatment. Dis Aquat Org 45:203-207

Lerch C, Blaschke G (1998) Investigation of the stereoselective metabolism of praziquantel after incubation with rat liver microsomes by capillary electrophoresis and liquid chromatography-mass spectrometry. J Chromatogr Biomed Sci Appl 708:267-275

Li XQ, Bjorkman A, Andersson TB, Gustafsson LL, Masimirembwa CM (2003) Identification of human cytochrome P450s that metabolise anti-parasitic drugs and predictions of in vivo drug hepatic clearance from in vitro data. Eur J Clin Pharmacol 59:429-442

Meier H, Blaschke G (2000) Capillary electrophoresis-mass spectrometry, liquid chromatography-mass spectrometry and nanoelectrospray-mass spectrometry of praziquantel metabolites. J Chromatogr Biomed Sci Appl 748:221-231

Meier H, Blaschke G (2001) Investigation of praziquantel metabolism in isolated rat hepatocytes. J Pharm Biomed Anal 26:409-415

Mitchell AJ (1995) Importance of treatment duration for praziquantel used against larval digenetic trematodes in sunshine bass. J Aquat Anim Health 7:327-330

Rogstad A, Hormazabal V, Yndestad M (1987) Extraction of praziquantel from fish tissue and its determination by high-performance liquid chromatography. J Chromatog A 391:328-333

Sanmartin Duran ML, Caamano-Garcia F, Fernandez Casal J, Leiro J, Ubeira FM (1989) Anthelmintic activity of praziquantel, niclosamide, netobimin and mebendazole against Bothriocephalus scorpii naturally infecting turbot (Scophthalmus maximus). Aquaculture 76:199-201

Schepmann D, Blaschke G (2001) Isolation and identification

Editorial responsibility: Stewart Johnson,

Halifax, Nova Scotia, Canada of 8-hydroxypraziquantel as a metabolite of the antischistosomal drug praziquantel. J Pharm Biomed Anal 26: 791-799

Schmahl G, Mehlhorn H (1985) Treatment of fish parasites. 1. Praziquantel effective against monogenea (Dactylogyrus vastator, Dactylogyrus extensus, Diplozoon paradoxum). Parisitol Res 71:727-737

Schmahl G, Taraschewski H (1987) Treatment of fish parasites. 2. Effects of praziquantel, niclosamide, levamisole$\mathrm{HCl}_{\text {, }}$ and metrifonate on monogenea (Gyrodactylus aculeati, Diplozoon paradoxum). Parasitol Res 73:341-351

Sharp N, Diggles BK, Poortenaar CW, Willis TJ (2004) Efficacy of Aqui-S, formalin and praziquantel against the monogeneans, Benedenia seriolae and Zeuxapta seriolae, infecting yellowtail kingfish Seriola lalandi lalandi in New Zealand. Aquaculture 236:67-83

Staudt U, Schmahl G, Blaschke G, Mehlhorn H (1992) Light and scanning electron microscopy studies on the effects of the enantiomers of praziquantel and its main metabolite on Schistosoma-mansoni in-vitro. Parasitol Res 78: 392-397

Stegeman JJ, Woodin BR, Singh H, Oleksiak MF, Celander M (1997) Cytochromes P450 (CYP) in tropical fishes: catalytic activities, expression of multiple CYP proteins and high levels of microsomal P450 in liver of fishes from Bermuda. Comp Biochem Physiol C Pharmacol Toxicol Endocrinol 116:61-75

Stephens FJ, Cleary JJ, Jenkins G, Jones JB, Raidal SR, Thomas JB (2003) Treatments to control Haliotrema abaddon in the West Australian dhufish, Glaucosoma hebraicum. Aquaculture 215:1-10

Thoney DA (1990) The effects of trichlorfon, praziquantel and copper sulphate on various stages of the monogenean Benedeniella posterocolpa, a skin parasite of the cownose ray, Rhinoptera bonasus (Mitchill). J Fish Dis 13:385-389

Tubbs LA, Tingle MD (2006a) Bioavailability and pharmacokinetics of a praziquantel bolus in kingfish Seriola lalandi. Dis Aquat Org 69:233-238

Tubbs LA, Tingle MD (2006b) Effect of dose escalation on multiple dose pharmacokinetics of orally administered praziquantel in kingfish Seriola lalandi. Aquaculture 261: 1168-1174

Xiao SH, Catto BA (1989) Comparative in vitro and in vivo activity of racemic praziquantel and its levorotated isomer on Schistosoma mansoni. J Infect Dis 159:589-592

Xiao SH, You JQ, Guo HF, Catto BA (1991) Uptake and effect of praziquantel and the major human oxidative metabolite 4 hydroxypraziquantel by Schistosoma japonicum. J Parasitol 77:241-245

Submitted: May 20, 2007; Accepted: October 13, 2007

Proofs received from author(s): December 11, 2007 